\title{
Transmission Studies Resume For Avian Flu
}

RON A. M. FOUCHIER ${ }^{1}$, ADOLFO GARCÍA-SASTRE ${ }^{2}$, YOSHIHIRO KAWAOKA ${ }^{3,4,{ }^{*}, \text { WENDY }}$ S. BARCLAY ${ }^{5}$, NICOLE M. BOUVIER ${ }^{6,2}$, IAN H. BROWN ${ }^{7}$, ILARIA CAPUA ${ }^{8}$, HUALAN CHEN ${ }^{9}$, RICHARD W. COMPANS ${ }^{10}$, ROBERT B. COUCH ${ }^{11}$, NANCY J. COX ${ }^{12}$, PETER C. DOHERTY ${ }^{13}$, RUBEN O. DONIS ${ }^{12}$, HEINZ FELDMANN ${ }^{14}$, YI GUAN ${ }^{15}$, JACQUELINE M. KATZ $^{12}$, OLEG I. KISELEV ${ }^{16}$, H. D. KLENK ${ }^{17}$, GARY KOBINGER ${ }^{18}$, JINHUA LIU ${ }^{19}$, XIUFAN LIU $^{20}$, ANICE LOWEN ${ }^{21}$, THOMAS C. METTENLEITER ${ }^{22}$, ALBERT D. M. E. OSTERHAUS ${ }^{1}$, PETER PALESE ${ }^{2}$, J. S. MALIK PEIRIS ${ }^{23}$, DANIEL R. PEREZ ${ }^{24}$, JÜRGEN A. RICHT ${ }^{25}$, STACEY SCHULTZ-CHERRY ${ }^{26}$, JOHN STEEL ${ }^{21}$, KANTA SUBBARAO ${ }^{27}$, DAVID E. SWAYNE ${ }^{28}$, TORU TAKIMOTO ${ }^{29}$, MASATO TASHIRO ${ }^{30}$, JEFFERY K. TAUBENBERGER ${ }^{31}$, PAUL G. THOMAS ${ }^{13}$, RALPH A. TRIPP ${ }^{32}$, TERRENCE M. TUMPEY ${ }^{12}$, RICHARD J. WEBBY $^{26}$, and ROBERT G. WEBSTER ${ }^{26}$

1Department of Virology, Erasmus Medical Center, 3015GE Rotterdam, Netherlands

${ }^{2}$ Department of Microbiology, Icahn School of Medicine at Mount Sinai, New York, NY 10029 , USA

${ }^{3}$ Department of Pathobiological Sciences, School of Veterinary Medicine, University of Wisconsin-Madison, Madison, WI 53711, USA

${ }^{4}$ Division of Virology, Department of Microbiology and Immunology, The Institute of Medical Science, University Of Tokyo, Minatoku, Tokyo 108-8639, Japan

${ }^{5}$ Department of Medicine, Imperial College, London, W2 1PG, UK

${ }^{6}$ Division of Infectious Diseases, Icahn School of Medicine at Mount Sinai, New York, NY 10029, USA

${ }^{7}$ Virology Department, Animal Health and Veterinary Laboratories Agency, Addlestone, KT15, UK

${ }^{8}$ Istituto Zooprofilattico Sperimentale delle Venezie, 35020, Padova, Italy

${ }^{9}$ Harbin Veterinary Research Institute, CAAS, Harbin 150001, China

${ }^{10}$ Influenza Pathogenesis and Immunology Research Center, Emory University, School of Medicine, Atlanta, GA 30322, USA

${ }^{11}$ Department of Molecular Virology and Microbiology, Baylor College of Medicine, Houston, TX 77030, USA

${ }^{12}$ Influenza Division, Centers for Disease Control and Prevention, Atlanta, GA 30333, USA

${ }^{13}$ Department of Immunology, St. Jude Children's Research Hospital, Memphis, TN 38105, USA

${ }^{14}$ Laboratory of Virology, National Institute of Allergy and Infectious Diseases, National Institutes of Health, Rocky Mountain Laboratories, Hamilton, MT 59840, USA

${ }^{15}$ State Key Laboratory of Emerging Infectious Diseases, School of Public Health, The University of Hong Kong, Hong Kong SAR

${ }^{16}$ D.I. Ivanovsky Institute of Virology, Ministry of Public Health, Moscow, Russia

${ }^{17}$ Institut für Virologie, 35043 Marburg, Germany 
${ }^{18}$ National Microbiology Laboratory, Public Health Agency of Canada, Winnipeg, MB R3E 3R2, Canada

${ }^{19}$ Department of Preventative Veterinary Medicine, China Agricultural University, Beijing, 100193, China

${ }^{20}$ Animal Infectious Disease Laboratory, School of Veterinary Medicine, Yangzhou University, Yangzhou, Jiangsu 225009, China

${ }^{21}$ Department of Microbiology and Immunology, Emory University School of Medicine, Atlanta, GA 30322, USA

${ }^{22}$ Friedrich-Loeffler-Institut, D-17493 Greifswald-Insel Riems, Germany

${ }^{23}$ Centre of Influenza Research, School of Public Health, The University of Hong Kong, Hong Kong SAR

${ }^{24}$ Department of Veterinary Medicine, University of Maryland, College Park, College Park, MD 20742, USA

${ }^{25}$ College of Veterinary Medicine, Kansas State University, Manhattan, KS 66506, USA

${ }^{26}$ Department of Infectious Diseases, St. Jude Children's Research Hospital, Memphis, TN 38105, USA

${ }^{27}$ Emerging Respiratory Viruses Section, Laboratory of Infectious Diseases, National Institute of Allergy and Infectious Diseases, National Institutes of Health, Bethesda, MD 20892-3203, USA

${ }^{28}$ Southeast Poultry Research Laboratory, USDA/Agricultural Research Service, Athens, GA 30605, USA

29Department of Microbiology and Immunology, University of Rochester Medical Center, Rochester, NY 14642, USA

${ }^{30}$ Influenza Virus Research Center, National Institute of Infectious Diseases, Tokyo, 208-0011, Japan

${ }^{31}$ Viral Pathogenesis and Evolution Section, Laboratory of Infectious Diseases, National Institute of Allergy and Infectious Diseases, National Institutes of Health, Bethesda, MD 20892-3203 USA

${ }^{32}$ Department of Infectious Diseases, College of Veterinary Medicine, University of Georgia, Athens, GA 30602, USA

In January 2012, influenza virus researchers from around the world announced a voluntary pause of 60 days on any research involving highly pathogenic avian influenza H5N1 viruses leading to the generation of viruses that are more transmissible in mammals (1). We declared a pause to this important research to provide time to explain the public health benefits of this work, to describe the measures in place to minimize possible risks, and to enable organizations and governments around the world to review their policies (for example, on biosafety, biosecurity, oversight, and communication) regarding these experiments.

During the past year, the benefits of this important research have been explained clearly in publications (2-7) and meetings (8-10). Measures to mitigate possible risks of the work have been detailed (11-13). The World Health Organization has released recommendations on laboratory biosafety for those conducting this research (14), and relevant authorities in several countries have reviewed the biosafety, biosecurity, and funding conditions under which further research would be conducted on the laboratory-modified H5N1 viruses (10, 15-17). Thus, acknowledging that the aims of the voluntary moratorium have been met in 
some countries and are close to being met in others, we declare an end to the voluntary moratorium on avian flu transmission studies.

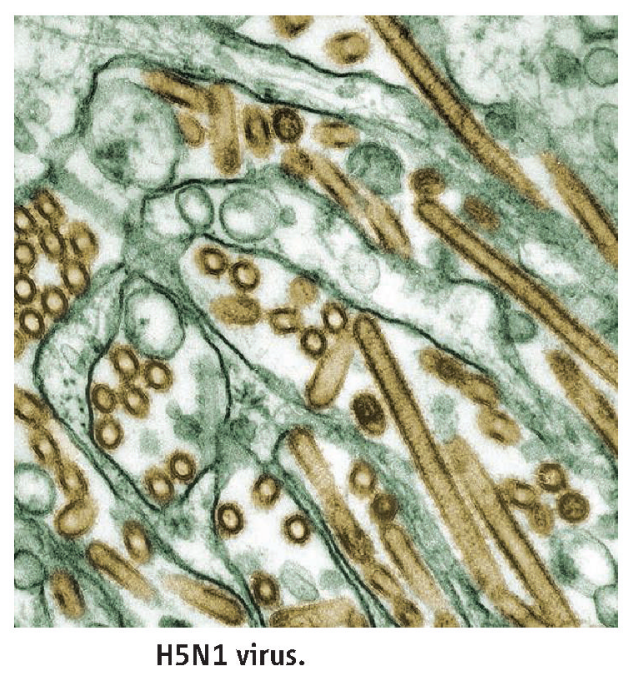

The controversy surrounding H5N1 virus transmission research has highlighted the need for a global approach to dealing with dualuse research of concern. Developing comprehensive solutions to resolve all the issues will take time. Meanwhile, H5N1 viruses continue to evolve in nature. Because $\mathrm{H} 5 \mathrm{~N} 1$ virus transmission studies are essential for pandemic preparedness and understanding the adaptation of influenza viruses to mammals, researchers who have approval from their governments and institutions to conduct this research safely, under appropriate biosafety and biosecurity conditions, have a public health responsibility to resume this important work. Scientists should not restart their work in countries where, as yet, no decision has been reached on the conditions for H5N1 virus transmission research. At this time, this includes the United States and U.S.-funded research conducted in other countries. Scientists should never conduct this type of research without the appropriate facilities, oversight, and all the necessary approvals. We consider biosafety level 3 conditions with the considerable enhancements (BSL-3+) outlined in the referenced publications (11-13) as appropriate for this type of work, but recognize that some countries may require BSL-4 conditions in accordance with applicable standards (such as Canada). We fully acknowledge that this research — as with any work on infectious agents—is not without risks. However, because the risk exists in nature that an H5N1 virus capable of transmission in mammals may emerge, the benefits of this work outweigh the risks.

\section{References}

1. Fouchier RAM, et al. Science. 2012; 335:400. [PubMed: 22282787]

2. Fouchier RAM, Herfst S, Osterhaus ADME. Science. 2012; 335:662. [PubMed: 22267582]

3. Herfst S, Osterhaus AD, Fouchier RA. J. Infect. Dis. 2012; 205:1628. [PubMed: 22454474]

4. Kawaoka Y. Nature. 2012; 482:155. [PubMed: 22278057]

5. Yen HL, Peiris JS. Nature. 2012; 486:332. [PubMed: 22722190]

6. Morens DM, Subbarao K, Taubenberger JK. Nature. 2012; 486:335. [PubMed: 22722191]

7. Fauci AS, Collins FS. Science. 2012; 336:1522. [PubMed: 22723407]

8. World Health Organization (WHO). Report on technical consultation on H5N1 research issues. WHO; Geneva: 2012. www.who.int/influenza/human_animal_interface/mtg_report_h5n1.pdf

9. National Science Advisory Board for Biosecurity. Meeting of the National Science Advisory Board for Biosecurity to review revised manuscripts on transmissibility of $\mathrm{A} / \mathrm{H} 5 \mathrm{~N} 1$ influenza virus: 
Statement of the NSABB; 2012; Mar. 2012 http://oba.od.nih.gov/oba/biosecurity/PDF/ NSABB_Statement_March_2012_Meeting.pdf

10. Gain-of-Function Research on Highly Pathogenic Avian Influenza H5N1 Viruses: An International Consultative Workshop; Bethesda, MD. 17-18 December 2012; http://oba.od.nih.gov/oba/ biosecurity/meetings/Dec2012/Agenda-Dec-17-18-2012-HHS-Meeting-GOF\%20Research-onHPAI-H5N1.pdf

11. Garcia-Sastre A. MBio. 2012; 3:e00049. [PubMed: 22396483]

12. Imai M, et al. Nature. 2012; 486:420. [PubMed: 22722205]

13. Herfst S, et al. Science. 2012; 336:1534. [PubMed: 22723413]

14. WHO. Influenza, Guidance for adoption of appropriate risk control measures to conduct safe research on H5N1 transmission. 2012. www.who.int/influenza/human_animal_interface/ biosafety_summary/en/index.html

15. Public Health Agency of Canada. Biosafety Advisory: Efficiently Transmissible Engineered Influenza A H5N1 Viruses. 2012. www.phac-aspc.gc.ca/lab-bio/res/advi-avis/sbn-asb-2012-01-31eng.php

16. Commissie Genetische Modificatie, Publications. Letter in response to influenza research Erasmus MC (CGM/111125-04). Mar 21. 2012 (2012); www.cogem.net/index.cfm/nl/publicaties/ publicatie/brief-navinfluenza-onderzoek-erasmus-mc [in Dutch]

17. United States Government Policy for Oversight of Life Sciences Dual Use Research of Concern. 2012. http://oba.od.nih.gov/oba/biosecurity/PDF/

United_States_Government_Policy_for_Oversight_of_DURC_FINAL_version_032812.pdf 